\title{
Waste Water Treatment Methods
}

\author{
Adina Elena Segneanu, Cristina Orbeci, Carmen Lazau, \\ Paula Sfirloaga, Paulina Vlazan, Cornelia Bandas and Ioan Grozescu
}

Additional information is available at the end of the chapter

http://dx.doi.org/10.5772/53755

\section{Introduction}

The last decades have shown a reevaluation of the issue of environmental pollution, under all aspects, both at regional and at international level. The progressive accumulation of more and more organic compounds in natural waters is mostly due to the development and extension of chemical technologies for organic synthesis and processing.

Population explosion, expansion of urban areas increased adverse impacts on water resources, particularly in regions in which natural resources are still limited. Currently, water use and reuse has become a major concern. Population growth leads to significant increases in default volumes of waste water, which makes it an urgent imperative to develop effective and affordable technologies for wastewater treatment.

The physico-chemical processes common treatment (coagulation and flocculation) using various chemical reagents (aluminum chloride or ferric chloride, polyelectrolytes, etc.) and generates large amounts of sludge. Increasing demands for water quality indicators and drastic change regulations on wastewater disposal require the emergence and development of processes more efficient and more effective (ion exchange, ultrafiltration, reverse osmosis and chemical precipitation, electrochemical technologies). Each of these treatment methods has advantages and disadvantages.

Water resources management exercises ever more pressing demands on wastewater treatment technologies to reduce industrial negative impact on natural water sources. Thus, the new regulations and emission limits are imposed and industrial activities are required to seek new methods and technologies capable of effective removal of heavy metal pollution loads and reduction of wastewater volume, closing the water cycle, or by reusing and recycling water waste.

Advanced technologies for wastewater treatment are required to eliminate pollution and may also increase pollutant destruction or separation processes, such as advanced oxidation 
methods (catalytic and photocatalytic oxidation), chemical precipitation, adsorption on various media, etc.. These technologies can be applied successfully to remove pollutants that are partially removed by conventional methods, e.g. biodegradable organic compounds, suspended solids, colloidal substances, phosphorus and nitrogen compounds, heavy metals, dissolved compounds, microorganisms that thus enabling recycling of residual water. (Zhou, 2002) Special attention was paid to electrochemical technologies, because they have advantages: versatility, safety, selectivity, possibility of automation, environmentally friendly and requires low investment costs (Chen, 2004; Hansen et. al., 2007).

The technologies for treating wastewater containing organic compounds fall within one of the following categories:

- Non-destructive procedures - based on physical processes of adsorption, removal, stripping etc.

- Biological destructive procedures - based on biological processes using active mud.

- Oxidative destructive processes - based on oxidative chemical processes which, in their turn, can fall within one of the following categories:

- Incineration;

- WO - "Wet Oxidation", operating in conditions of high temperature and pressure, with the versions:

- WAO - "Wet Air Oxidation" (wet oxidation with $\mathrm{O}_{2}$ air oxidative agent);

- CWAO - "Catalytic Wet Air Oxidation" (catalytic wet oxidation with $\mathrm{O}_{2}$ air oxidative agent);

- $\quad$ SWA - "Supercritical Water Oxidation" (oxidation with $\mathrm{O}_{2}$ air oxidative agent in supercritical conditions).

- Liquid oxidation: AOPs - "Advanced Oxidation Processes", operating in conditions of temperature and pressure and use as oxidative agents $\mathrm{O}_{3}, \mathrm{H}_{2} \mathrm{O}_{2}$ and even $\mathrm{O}_{2}$, catalysts and/ or UV radiations.

\section{Advanced oxidation processes}

Advanced oxidation processes (AOPs) are widely used for the removal of recalcitrant organic constituents from industrial and municipal wastewater. In this sense, AOP type procedures can become very promising technologies for treating wastewater containing non-biodegradable or hardly biodegradable organic compounds with high toxicity. These procedures are based on generating highly oxidative $\mathrm{HO}$ radicals in the reaction medium.

- $\mathrm{H}_{2} \mathrm{O}_{2}$

$$
\begin{aligned}
& \mathrm{H}_{2} \mathrm{O}_{2}+\mathrm{UV} \text { (direct photolysis) } \\
& \mathrm{H}_{2} \mathrm{O}_{2}+\mathrm{Fe}^{2+/ 3+} \text { (classic, homogeneous Fenton) } \\
& \mathrm{H}_{2} \mathrm{O}_{2}+\mathrm{Fe} \text { /support (heterogeneous Fenton) } \\
& \mathrm{H}_{2} \mathrm{O}_{2}+\mathrm{Fe}^{2+/ 3+}+\mathrm{UV} \text { (VIS) (Photo-Fenton) }
\end{aligned}
$$


- $\mathrm{O}_{3}$

$\mathrm{O}_{3}$ (direct ozone feeding)

$\mathrm{O}_{3}+\mathrm{UV}$ (photo-ozone feeding)

$\mathrm{O}_{3}+$ catalysts (catalytic ozone feeding)

- $\mathrm{H}_{2} \mathrm{O}_{2}+\mathrm{O}_{3}$

$\mathrm{TiO}_{2}$ (heterogeneous catalysis)

$\mathrm{TiO}_{2}+\mathrm{UV}$ (photo-catalysis)

The preferential use of $\mathrm{H}_{2} \mathrm{O}_{2}$ as oxidative agent and $\mathrm{HO}$ radicals generator is justified by the fact that the hydrogen peroxide is easy to store, transported and used, and the procedure is safe and efficient.

The technologies developed so far indicate the use of zeolites, active coal, structured clay, silica textures, Nafion membranes or Fe under the form of goethit $(\alpha-\mathrm{FeOOH})$, as support materials for the catalytic component.

The AOPs (Advanced Oxidation Processes) can be successfully used in wastewater treatment to degrade the persistent organic pollutants, the oxidation process being determined by the very high oxidative potential of the $\mathrm{HO}$ radicals generated into the reaction medium by different mechanisms (Pera-Titus et al., 2004).

AOPs can be applied to fully or partially oxidize pollutants, usually using a combination of oxidants. Photo-chemical and photocatalytic advanced oxidation processes including $\mathrm{UV} / \mathrm{H}_{2} \mathrm{O}_{2}, \mathrm{UV} / \mathrm{O}_{3}, \mathrm{UV} / \mathrm{H}_{2} \mathrm{O}_{2} / \mathrm{O}_{3}, \mathrm{UV} / \mathrm{H}_{2} \mathrm{O}_{2} / \mathrm{Fe}^{2+}\left(\mathrm{Fe}^{3+}\right), \mathrm{UV} / \mathrm{TiO}_{2}$ and $\mathrm{UV} / \mathrm{H}_{2} \mathrm{O}_{2} / \mathrm{TiO}_{2}$ can be used for oxidative degradation of organic contaminants. A complete mineralization of the organic pollutants is not necessary, being more worthwhile to transform them into biodegradable aliphatic carboxylic acids followed by a biological process (Wang and Wang, 2007).

The oxidation process is determined by the very high oxidative potential of the HO radicals generated into reaction medium by different mechanisms. In the case of the AOPs Fentontype procedure (hydrogen peroxide and $\mathrm{Fe}^{2+}$ as catalyst), the generation of hydroxyl radicals takes place through a catalytic mechanism in which the iron ions play a very important role (Andreozzi et al., 1999; Esplugas, et al., 2002) the main reactions involved being presented in equations (1) - (4):

$$
\begin{gathered}
\mathrm{Fe}^{2+}+\mathrm{H}_{2} \mathrm{O}_{2} \rightarrow \mathrm{Fe}^{3+}+\mathrm{HO}^{-}+\mathrm{HO} \\
\mathrm{Fe}^{3+}+\mathrm{H}_{2} \mathrm{O}_{2} \leftrightarrow \mathrm{H}^{+}+[\mathrm{Fe}(\mathrm{OOH})]^{2+} \\
{[\mathrm{Fe}(\mathrm{OOH})]^{2+} \rightarrow \mathrm{Fe}^{2+}+\mathrm{HO}_{2} .} \\
\mathrm{HO}_{2}+\mathrm{Fe}^{3+} \rightarrow \mathrm{Fe}^{2+}+\mathrm{H}^{+}+\mathrm{O}_{2}
\end{gathered}
$$


In the presence of UV radiations (photo-Fenton process), an additional number of $\mathrm{HO}$ radicals are produced both through direct $\mathrm{H}_{2} \mathrm{O}_{2}$ photolysis and through $\mathrm{UV}$ radiations interaction with the iron species in aqueous solutions (eq. 5-7) (Spacek et al., 1995; Pignatello, J.J., 1992):

$$
\begin{gathered}
\mathrm{H}_{2} \mathrm{O}_{2}+\mathrm{UV} \rightarrow 2 \mathrm{HO} \\
\mathrm{Fe}^{3+}+\mathrm{H}_{2} \mathrm{O}+\mathrm{UV} \rightarrow \mathrm{Fe}^{2+}+\mathrm{H}^{+}+\mathrm{HO} . \\
{[\mathrm{Fe}(\mathrm{OH})]^{2+}+\mathrm{UV} \rightarrow \mathrm{Fe}^{2+}+\mathrm{HO} .}
\end{gathered}
$$

The main parameters which determine the efficiency of the oxidation process are: the structure of the organic compounds, the hydrogen peroxide and the catalyst concentrations, the wave length and intensity of UV radiations, the initial solution ph and the reaction contact time.

As recalcitrant organic pollutants continue to increase in air and wastewater streams, environmental laws and regulations become more stringent (Gayaa et al, 2008). The main causes of surface and groundwater contamination are industrial effluents (even in small amounts), excessive use of pesticides, fertilizers (agrochemicals) and domestic waste landfills. Wastewater treatment is usually based on physical and biological processes. After elimination of particles in suspension, the usual process is biological treatment (natural decontamination), but unfortunately, some organic pollutants, classified as bio-recalcitrant, are not biodegradable. In this way advanced oxidation processes (AOPs) may become the most widely used water treatment technologies for organic pollutants not treatable by conventional techniques due to their high chemical stability and/or low biodegradability (Munoz et al.2005). Advanced oxidation processes are indicated for removal of organic contaminants such as halogenated hydrocarbons (trichloroethane, trichlorethylene), aromatics (benzene, toluene, and xylene), pentachlorophenol (PCP), nitrophenol, detergents, pesticides, etc. These processes can also be applied to oxidation of inorganic contaminants such as cyanides, sulfides and nitrites (Munter, 2001). A general classification of advanced oxidation processes based on source allowing radicals. This classification is presented in Figure 1.

Heterogeneous photocatalysis has proved to be of real interest as efficient tool for degrading both aquatic and atmospheric organic contaminants because this technique involved the acceleration of photoreaction in presence of semiconductor photocatalyst (Guillard, 1999). Thus these processes can be classified in: advanced oxidation processes based on ozone based advanced oxidation processes $\mathrm{H}_{2} \mathrm{O}_{2}$, photocatalysis, POA "hot" technologies based on ultrasound, electrochemical oxidation process, oxidation processes with electron beam. These processes involve generation and subsequent reaction of hydroxyl radicals (_OH), which are one of the most powerful oxidizing species. Photocatalytic reaction is initiated when a photoexcited electron is promoted from the filled valence band of semiconductor photocatalyst to the empty conduction band as the absorbed photon energy, $h \_$equals or exceeds the band gap of the semiconductor photocatalyst leaving behind a hole in the valence band. Thus in concert, electron and hole pair $\left(\mathrm{e}^{--} \mathrm{h}+\right)$ is generated (Horvath, 2003). An ideal photocatalyst for photocatalytic oxidation is characterized by the following attributes: photo-stability, chemically and biologically inert nature, availability and low cost 
(Carp et. al., 2004). Many semiconductors such as $\mathrm{TiO}_{2}$ (Lazau, 2011), $\mathrm{ZnO}$ (Daneshvar et al., 2007), $\mathrm{ZrO}_{2}$ (Lopez et al. 2007), CdS (Yingchun, 2011), $\mathrm{MoS}_{2}$ (Kun Hong, 2011), $\mathrm{Fe}_{2} \mathrm{O}_{3}$ (Seiji, 2009) and $\mathrm{WO}_{3}$ (Yuji, 2011) have been examined and used as photocatalysts for the degradation of organic contaminants. $\mathrm{TiO}_{2}$ is most preferred one due to its chemical and biological inertness, high photocatalytic activity, photodurability, mechanical robustness and cheapness. Thus, these materials were used in the degradation of phenol, 1,4dichlorobenzene (Papp et al., 1993), methanol (Nobuaki et. al., 2007), azo dye (Daneshvar, 2003), trichloromethane, hexachloro cyclohexane (Byrappa et. al., 2002 ), trichloroethylene and dichloropropionic acid (Nikola, 2001). To avoid the problem of filtration, many methods were proposed to immobilize the photocatalysts, but in these conditions the photocatalyst is expected to be used for a relatively long time, especially for industrial applications (Venkata, 2004). Various substrates have been used as a catalyst support for the photocatalytic degradation of polluted water. For example glass materials: glass mesh, glass fabric, glass wool, glass beads and glass reactors were very commonly used as a support for titania. Other uncommon materials such as microporous cellulosic membranes, alumina clays, ceramic membranes, monoliths, zeolites, and even stainless steel were also experimented as a support for $\mathrm{TiO} 2$ (Gianluca, 2008).

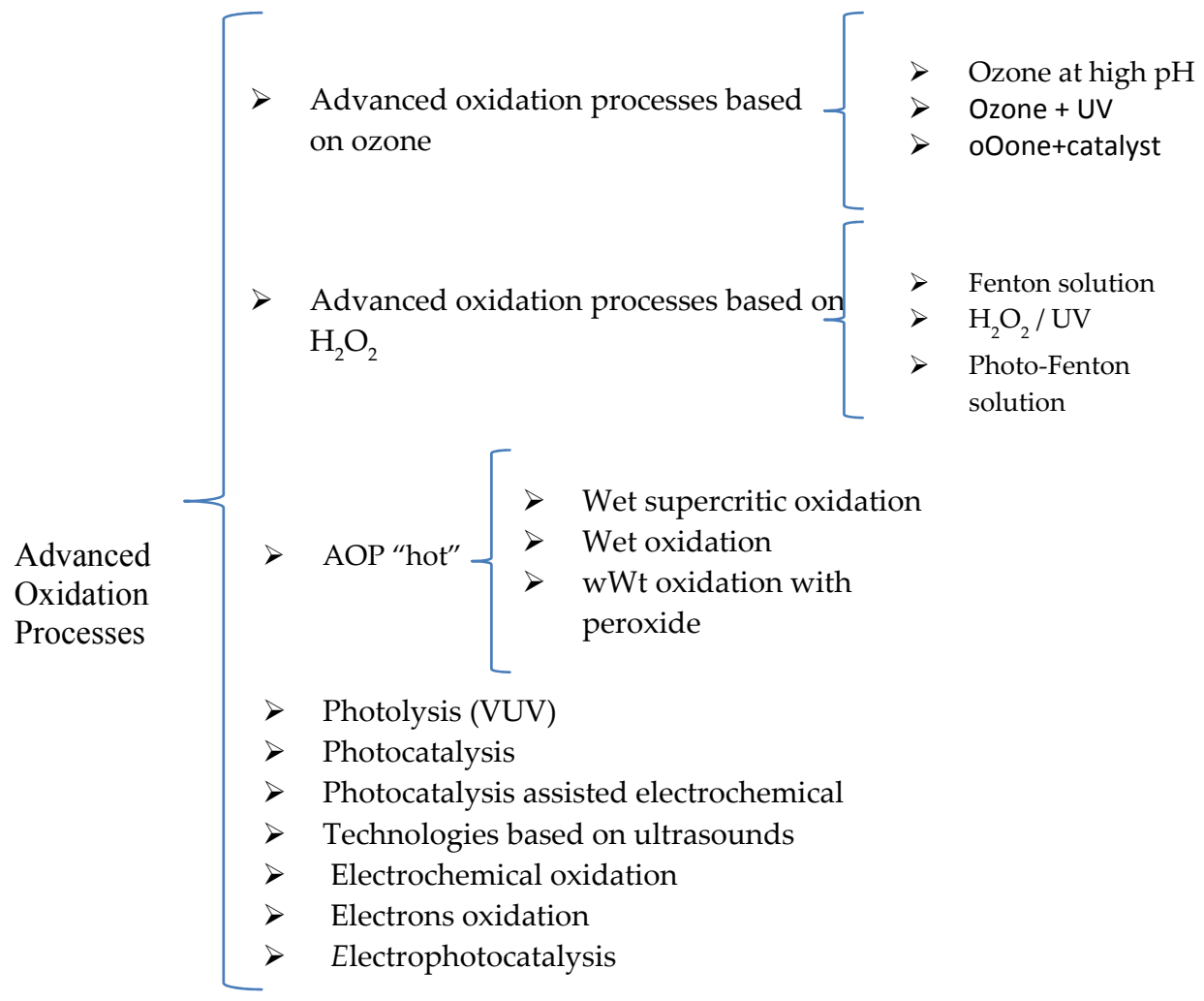

Figure 1. Classification of advanced oxidation processes 
Advanced oxidation processes (AOPs) and electrochemical oxidation is based on the in-situ generation of $\mathrm{OH}$ radicals, which allow its non-selective reaction with organics allowing organics mineralization by its conversion into $\mathrm{CO}_{2}$. The electrochemical methods are very promising alternatives for organics degradation because of their environmental compatibility, versatility, simplicity, and easy possibility of automation. The electrochemical oxidation performance depends strongly on the electrode material. To generate $\mathrm{OH}$ radicals by electrooxidation, several types of anodes with high overpotential for oxygen potential are suitable, i.e., DSA-type, $\mathrm{PbO}_{2}$, boron-doped diamond (BDD) electrodes etc. Recently, electrochemical oxidation with a boron-doped diamond electrode is one of the most promising technologies in the treatment of the industrial effluents containing organics. BDD electrode exhibited a very good chemical stability and its application in the electrooxidation of organics led to complete mineralization into $\mathrm{CO}_{2}$ in relation with applied potential or current density. A major drawback of the electrochemical oxidation consists of the high energy consumption to the mineralization. The presence of a catalyst in the electrical field or combined and direct photoelectrochemical application can enhance the treatment efficiency with lower energy consumption (Ratiu et. al., 2010).

Electrochemical and photochemical technologies may offer an efficient means of controlling pollution. Their effectiveness is based on the generation of highly reactive and non-selective hydroxyl radicals, which are able to degrade many organic pollutants. Electrolysis, heterogeneous photocatalysis, or photo-assisted electrolysis may be regarded as advanced oxidation processes (AOPs) and used in the supplementary treatment of wastewaters. The efficiency of the electrochemical oxidation depends on the anode material and the operating conditions, e.g., current density or potential. In general, in most applications of photoelectrocatalysis in the degradation of organics, the applied anodic bias potential is lower than the oxidation potential of organics on the electrode, due to direct electrooxidation does not complicate the photocatalytic mechanism (Ratiu et. al.,2011).

The efficiency of photoelectrochemical degradation for organic pollutants depends not only on the selection of a suitable supporting electrolyte and $\mathrm{pH}$ values, but also on the electrode potential and preparation conditions of the semiconductors involved. In a photoelectrochemical system, photoelectrons and photoholes can be separated under the influence of an applied electric field. The problem of the separation of semiconductor particles from the treated solution, so persistent in heterogeneous photolysis, is not an issue in photoelectrochemical systems. There are numerous semiconductors which can be used as photoelectrocatalytic materials, such as $\mathrm{TiO}_{2}, \mathrm{WO}_{3}, \mathrm{SnO}_{2}, \mathrm{ZnO}, \mathrm{CdS}$, diamond, and others (Hepel 2005).

\subsection{Particular aspects}

In the case of the chlorinated phenols, the number and the position on aromatic ring of the chlorine atoms modifies the oxidation efficiency (Pera-Titus et al., 2004).

The oxidation rate constant decreases linearly with increasing number of chlorine content on the aromatic ring. Also, the increase of chlorine content will block some favorable positions susceptible to hydroxyl radical attack. 
The oxidation process is also controlled by the presence of another species in reaction medium (intermediate products) in the sense that they interact with the catalyst component in a different manner. The species of reductive character accelerate the oxidation process because they reduce $\mathrm{Fe}^{3+}$ (inactive) to $\mathrm{Fe}^{2+}$ (active) and thus the generation of $\mathrm{OH}$ radicals intensifies ( $\mathrm{Du}$ et al. 2006; Riga, A., et al, 2007). The acid type species lower the $\mathrm{pH}$ of the reaction medium and can form stable complexes with $\mathrm{Fe}^{3+}$ or $\mathrm{Fe}^{2+}$ ions, strongly slowing the oxidation process. The presence into reaction medium of the inorganic ionic species $\left(\mathrm{Cl}^{-}, \mathrm{ClO}_{4}{ }^{-}, \mathrm{NO}_{3}{ }^{-}, \mathrm{HCO}_{3}{ }^{-}, \mathrm{CO}_{3}{ }^{2-}, \mathrm{SO}_{4}{ }^{2-}, \mathrm{H}_{2} \mathrm{PO}_{4}{ }^{-}\right)$modifies the rate of the oxidation of the organic compounds as function of their nature and concentration. The inorganic anions can change the overall efficiency of the system by different ways. The influence of $\mathrm{ClO}_{4}^{-}$ and $\mathrm{NO}_{3}^{-}$ions is less pronounced than another anions because they do not form complexes with Fe(II) and Fe(III) and do not react with HO (Lu et al., 1997; Siedlecka, E. M., 2007). $\mathrm{Cl}^{-}, \mathrm{SO}_{4}{ }^{2-}$ and $\mathrm{H}_{2} \mathrm{PO}_{4}^{--}$anions decrease the rate of decomposition of $\mathrm{H}_{2} \mathrm{O}_{2}$ by forming ferric unreactive complexes and react with hydroxyl radicals forming $\mathrm{Cl}_{2}^{-}, \mathrm{SO}_{4}-$ and $\mathrm{H}_{2} \mathrm{PO}_{4}$ - radicals who are less or much less reactive than HO (Siedlecka, E. M., 2007; De Laat et al., 2004). The influence of $\mathrm{Cl}^{-}$is in correlation with the solution $\mathrm{pH}$ and its concentration, being insignificant at low concentration $(<5 \mathrm{mM})$ but becomes very important at higher concentration values $(>28 \mathrm{mM}$ ) (Kwon et al., 1999). As function of the nature of the inorganic anions, at higher concentration of $0.1 \mathrm{M}$, the inhibition order of the oxidation rate is the following: $\mathrm{H}_{2} \mathrm{PO}_{4}^{-}>\mathrm{Cl}^{-}>\mathrm{HCO}_{3}^{-}>\mathrm{CO}_{3}{ }^{2-}>\mathrm{SO}_{4}{ }^{2-}>\mathrm{NO}_{3}^{-}$(Riga, A., et al., 2007).

The presence of the inorganic species inside the reaction medium influences the rate of the oxidation process as function of their nature and concentration. The inorganic anionic species reduce the 4-CP oxidation efficiency by $\mathrm{Fe}(\mathrm{II})$ and $\mathrm{Fe}(\mathrm{III})$ complexes forming, $\mathrm{HO}$. radicals scavenging or iron precipitate forming.

$\mathrm{NO}_{3}$ - induces a small influence on 4-CP oxidation efficiency. This may be explained by the absence of the interactions between $\mathrm{NO}_{3}{ }^{-}$and the catalyst $\left(\mathrm{Fe}^{2+/ 3+}\right)$ and hydroxyl radicals. The anions $\mathrm{Cl}^{-}, \mathrm{SO}_{4}{ }^{2-}$ and $\mathrm{PO}_{4}{ }^{3-}$ modify drastically the 4-CP oxidation efficiency, especially at high concentration into reaction medium. They interact with $\mathrm{Fe}^{2+}$ and $\mathrm{Fe}^{3+}$ forming chloro-, sulfato- and phosphate-iron complexes which are inactive in $\mathrm{HO}$ generation mechanism. Also, $\mathrm{Cl}^{-}, \mathrm{SO}_{4}^{2-}$ and $\mathrm{H}_{2} \mathrm{PO}_{4}^{-}$anions interact with hydroxyl radicals (scavenging process), forming less reactive species $\left(\mathrm{Cl}_{2}^{-}, \mathrm{SO}_{4}^{--}\right.$and $\left.\mathrm{H}_{2} \mathrm{PO}_{4} \cdot\right)$ into reaction medium.

The decrease of the 4-CP oxidation degree by the photo-Fenton procedure is correlated with the nature of the anions as following: $\mathrm{Cl}^{-}>\mathrm{PO}_{4}{ }^{3-}>\mathrm{SO}_{4}{ }^{2-}>>\mathrm{NO}_{3}^{-}$(Orbeci et al., 2008).

The presence of the insoluble inorganic species (bentonite) modifies the 4-CP oxidation efficiency in different manner. Into reaction medium, 4-CP can be adsorbed by the bentonite substratum or can be destruct by oxidation, both processes increasing the 4-CP removal degree from the solution. The presence of the insoluble inorganic species (bentonite) modifies the oxidation efficiency by additional 4-CP and UV sorption processes, especially at high solution turbidity values (Orbeci et al., 2008). 
The efficiency of the various AOPs depends both on the rate of generating the free radicals and the extent of contact between the radicals and the organic compound. Also, the $\mathrm{pH}$ has a significant role in determining the efficiency of Fenton and photo-Fenton oxidation processes (Gogate and Pandit, 2004). Limitations due to the use of homogeneous catalysts, such as limited $\mathrm{pH}$ range, production of Fe containing sludge, and deactivation could be overcome by heterogeneous catalysts.

The optimum $\mathrm{pH}$ range in the case of homogeneous photo-Fenton process is 2.5-4, a correction of solution $\mathrm{pH}$ being necessary. Also, at the end of the oxidation process, iron precipitation and catalyst separation and recovery are necessary. These disadvantages can be avoided using the heterogeneous photo-Fenton procedure by immobilization of active iron species on small particulate solid supports. In this case, different iron-containing catalysts can be used, such as the iron bulk catalysts (iron oxy-hydroxyl compounds: hematite, goethite, magnetite) or iron supported catalysts (zeolites, clays, bentonite, glass, active carbon, polymers etc.) (Duarte and Madeira, 2010; Feng et al., 2005; He et al., 2005; Leland and Bard, 1987; Nie et al., 2008; Ortiz de la Plata et al., 2010; Vinita et al. 2010).

The use of the heterogeneous photo-Fenton procedure in the catalytic component version (Fe in various oxidation states) precipitated on solid support presents several drawbacks:

- catalyst's relatively high cost - associated with the cost of the so-called support, with the cost of the Fe compounds and with the operations necessary for Fe compounds to fix on the support;

- decrease in the efficiency of the UV radiations due to their partial adoption on the solid support;

- $\quad$ progressive solubility of the catalytic component (Fe) during oxidative processes and as a result of a progressive loss of catalytic activity.

In the case of the heterogeneous photo-Fenton process, a relevant fraction of the incident UV radiation can be lost via scattering, due to particulate solid support suspended into the reaction medium. As a consequence, the photo-Fenton process may be seriously affected (Herney-Ramirez et al., 2010). Also, the solution $\mathrm{pH}$ affects the iron leaching from the support, at $\mathrm{pH}$ values less than 3 a higher amount of iron being released into the solution (Duarte and Madeira, 2010). By using a zero-valent iron with iron oxide composite catalysts, the oxidation process proceeds via hydroxyl radicals generated from $\mathrm{Fe}^{2+}$ (surf) species and $\mathrm{H}_{2} \mathrm{O}_{2}$ in a Fenton like mechanism. The $\mathrm{Fe}^{2+}$ (surf) species are formed by electron transfer from $\mathrm{Fe}^{0}$ to $\mathrm{Fe}^{3+}$ at the interface metal/oxide (Moura et al., 2005, 2006). The experimental data (Nie et al., 2008) indicate that the hydrogen peroxide provides a driving force in the electron transfer from $\mathrm{Fe}^{2+}$ to $\mathrm{Fe}^{3+}$, while the degradation of organic pollutants increases the electron transfer at the interface of $\mathrm{Fe}^{0}$ /iron oxide due to their reaction with hydroxyl radicals.

The degradation of organic pollutants using photo-Fenton processes occurs by intermediate oxidation products formation. In the case of phenol oxidation by Fenton reagent, a series of intermediates were identified, corresponding mainly to ring compounds and short-chain organic acids (Zazo et al., 2005). Most significant among the former were catechol, 
hydroquinone, and p-benzoquinone; the main organic acids were maleic, acetic, oxalic, and formic, with substantially lower amounts of muconic, fumaric, and malonic acids. Oxalic and acetic acid appeared to be fairly refractory to the Fenton oxidation process. In the Fenton process, carboxylic acids like acetic and oxalic acid may be formed as end products during the degradation of phenol while in photo-Fenton process, both these acids were identified during the early stages of phenol degradation and were oxidized almost completely at the end of the process (Kavitha and Palanivelu, 2004). The chlorophenols are common persistent organic contaminants, which show low biodegradability, posing serious risks to the environment once discharged into natural water ( $\mathrm{Du}$ et al., 2006).

Studying the degradation of 4-chlorophenol by an electrochemical advanced oxidation process, several authors (Wang and Wang, 2007) have proposed the following possible pathways: (a) 4-chlorophenol dechlorination to phenol; (b) hydroxylation of phenol to hydroquinone; (c) dehydrogenation of hydroquinone to benzoquinone; (d) oxidation of benzoquinone (with aromatic ring cleavage) to aliphatic carboxylic acids such as maleic acid, fumaric acid, malonic acid; (e) oxidation of maleic and fumaric acids to oxalic acid, formic acid and finally, to carbon dioxide and water.

The main intermediate products detected by HPLC analyses were chlorocatechol and benzoquinone after $60 \mathrm{~min}$ reaction time and aliphatic carboxylic acids after $120 \mathrm{~min}$ reaction time. Benzoquinone and hydroquinone-like intermediates such as catechol, hydroquinone and 4-chlorocatechol can reduce the ferric ion to ferrous ion and the oxidation process becomes faster ( $\mathrm{Du}$ et al., 2006). It is not necessary to degrade 4chlorophenol to the final products of $\mathrm{CO}_{2}$ and $\mathrm{H}_{2} \mathrm{O}$, being more worthwhile to treat to the biodegradable stage-aliphatic carboxylic acids followed by a biological process (Wang and Wang, 2007). The photocatalytic processes may be used as a pre-treatment of toxic chemicals, including chlorophenols, in order to convert them into fully biodegradable compounds.

Recently, a series of pharmaceuticals such as analgesics, antibiotics, steroids etc. have been detected in the water feeding systems of several countries in Europe, the USA and Australia (Bound and Voulvoulis, 2004; Kaniou et al., 2005). Unless antibiotics are removed from wastewaters through specific purification processes, they can affect the microbial communities in filtering systems using active sludge and, in general, the bacteria found in water, and, as a result, they can disturb the natural elementary cycles. The accumulation of antibiotics in surface waters represents a potential danger in the case in which they are used as sources of drinking water. Photocatalytic oxidation of antibiotics in aqueous solution is based on the oxidative potential of the $\mathrm{HO}$ radicals $(2.80 \mathrm{~V})$ generated in the reaction medium though photocatalytic mechanisms, in the presence of $\mathrm{H}_{2} \mathrm{O}_{2}$ and UV radiations. Through the photo-Fenton procedure, the efficiency of the oxidation is controlled by the nature and the structure of the organic substrate, the initial $\mathrm{pH}$ of the solution, the concentration of $\mathrm{H}_{2} \mathrm{O}_{2}$ and of the catalytic component $\left(\mathrm{Fe}^{2+}\right)$ as well as by the time the reaction medium stands in the area where UV radiations act.

The kinetic assessment of the oxidative degradation process applied to antibiotics of the type amoxicillin, ampicillin and streptomycin (pseudo $1^{\text {st }}$ degree Lagergren kinetic model) 
suggests that the oxidative process occurs in two successive steps, with the formation of reaction intermediates. The ratio of the $1^{\text {st }}$ degree kinetic constant values corresponding to the two oxidation stages depends on the structure of the antibiotics and indicates a marked decrease in the oxidation rate in the second stage. This decrease can be attributed to the formation of reaction intermediates such as inferior organic acids with a high stability in regard to oxidation and/or blocking active catalytic centers through the formation of compounds of the $\mathrm{Fe}^{2+/ 3+}$ species with the reaction intermediates, compounds which are inactive in the process of generating HOradicals (Orbeci et al., 2010).

Advanced oxidation processes of Fenton and photo-Fenton type can be used for antibiotics degradation from wastewater (Orbeci et al., 2010) or for increasing their biodegradability in biological wastewater treatment (Elmolla and Chaudhuri, 2009). Unlike complete amoxicillin degradation, the mineralization of the organic compounds from solution is not complete in the Fenton oxidation process due to formation of refractory intermediates (Ay and Kargi, 2010).

The photo-Fenton process degradation of amoxicillin by using iron species as catalyst ( $\mathrm{FeSO}_{4}$ and potassium ferrioxalate complex) and solar radiation reduces the bactericide effect of amoxicillin but the toxicity may persist due to intermediates formed during the oxidation process. The toxicity decreases significantly when these intermediates are converted into short chain carboxylic acids, allowing further conventional treatment (Trovó et al., 2011). The homogeneous photo-Fenton process is limited by the narrow working $\mathrm{pH}$ range (2.5-4) and requires the correction of solution $\mathrm{pH}$ for iron precipitation and catalyst separation and recovery. Otherwise, high amounts of metal-containing sludge can be formed and the catalytic metals are lost in these sludge. Because of these disadvantages, several attempts have been made to develop heterogeneous photo-Fenton procedure by immobilization of active iron species on solid supports. Since iron is relatively inexpensive and nontoxic, it has been widely used in different environmental treatment processes (Herney-Ramirez et al., 2010; Nie et al., 2008). In the heterogeneous photo-Fenton process, different iron-containing catalysts can be used, such as the iron bulk catalysts (iron oxyhydroxyl compounds: hematite, goethite, magnetite) or iron supported catalysts (zeolites, clays, bentonite, glass, active carbon, polymers etc.) (Feng et al., 2005; He et al., 2005; Leland and Bard, 1987; Nie et al., 2008; Ortiz de la Plata et al., 2010; Vinita et al. 2010).

Antibiotics can be more or less extensively metabolized by humans and animals. Depending on the quantities used and their rate of excretion, they are released in effluents and reach sewage treatment plants (Alexy et al., 2004; Bound and Voulvoulis, 2004; Kümmerer, 2009).

Available data on antibiotics (ampicillin, erythromycin, tetracycline and penicilloyl groups) indicate their capability to exert toxic effects to living organisms (bacteria, algae etc.), even at very low concentration. These antibiotics are practically non-biodegradable having the potential to survive sewage treatment, leading to a persistence of these compounds in the environment and a potential for bio-accumulation (Arslan-Alaton et al., 2004). The presence of antibiotics in the environment has favored the emergence of antibiotic-resistant bacteria, increasing the likelihood of infections as well as the need to find new and more powerful 
antibiotics. As expected, antibiotic-contaminated water is incompatible with conventional biological water treatment technologies (Rozas et al., 2010). Antibiotics have the potential to affect the microbial community in sewage systems and can affect bacteria in the environment and thus disturb natural elementary cycles (Kümmerer, 2009). If they are not eliminated during the purification process, they pass through the sewage system and may end up in the environment, mainly in the surface water.

This is of special importance, since surface water is a possible source of drinking water (Kaniou et al., 2005). The antibiotics degradation by advanced oxidation processes has proven to be reasonably suited and quite feasible for application as a pre-treatment method by combining with biological treatment (Arslan-Alaton et al., 2004). The pre-treatment of penicillin formulation effluent by advanced oxidation processes based on $\mathrm{O}_{3}$ and $\mathrm{H}_{2} \mathrm{O}_{2} / \mathrm{O}_{3}$ did not completely remove the toxicity of procaine penicillin $\mathrm{G}$ from the effluents, leading to serious inhibition of the treatment of activated sludge (Arslan-Alaton et al., 2006). One of the novel technologies for treating polluted sources of industrial wastewater and drinking water is the photo-Fenton process by which hydroxyl radicals are generated in the presence of $\mathrm{H}_{2} \mathrm{O}_{2}, \mathrm{Fe}^{2+}$ catalyst and UV radiation.

The advanced oxidation processes or even the hybrid methods may not be useful in degrading large quantity of the effluent with economic efficiency and hence it is advisable to use these methods for reducing the toxicity of the pollutant stream to a certain level beyond which biological oxidation can ensure the complete mineralization of the biodegradable products (Gogate and Pandit, 2004).

Removal of organic compounds in wastewater is a very important subject of research in the field of environmental chemistry. In this sense, photocatalysis is a handy promising technology, very attractive for wastewater treatment and water potabilization (Nikolaki et al., 2006; Lim et al., 2009). Using titanium dioxide for water splitting after UV irradiation, it has been shown that this can encompass a wide range of reactions, especially the oxidation of organic compounds. The study of the photodegradation for a large series of substances such as halogenated hydrocarbons, aromatics, nitrogenated heterocycles, hydrogen sulfide, surfactants and herbicides, and toxic metallicions, among others has clearly shown that the majority of organic pollutants present in waters can be mineralized or at least partially destroyed. The photocatalytic treatment of many organic compounds has been successfully achieved. The photocatalytic activity is dependent on the surface and structural properties of the semiconductor such as crystal composition, surface area, particle size distribution, porosity, band gap and surface hydroxyl density (Ahmed et al., 2010).

A variety of semiconductor powders (oxides, sulfides etc.) acting as photocatalysts have been used. Most attention has been given to $\mathrm{TiO}_{2}$ because of its high photocatalytic activity having a maximum quantum yields, its resistance to photo-corrosion, its biological immunity and low cost. There are two types of reactors: reactors with $\mathrm{TiO}_{2}$ suspended in the reaction medium and reactors with $\mathrm{TiO}_{2}$ fixed on a carrier material (Lim et al.; 2009, Mozia, 2010; Li et al., 2009). A very promising method for solving problems concerning the separation of the photocatalyst from the reaction medium is the application of 
photocatalytic membrane reactors (PMRs), having other advantages such as the realization of a continuous process and the control of a residence time of molecules in the reactor (Mozia, 2010). In case of polymer membranes, there is a danger for the membrane structure to be destroyed by UV light or hydroxyl radicals. The investigations described (Chin et al., 2006; Molinari et al., 2000) show that the lowest resistance exhibit membranes prepared from polypropylene, polyacrylonitrile, cellulose acetate and polyethersulfone, UV light leading to a breakage in the chemical bonds of the methyl group. The least effect of the UV/oxidative environment on the membrane stability was observed in case of polytetrafluoroethylene and polyvinylidene fluoride membranes (Chin et al., 2006).

The self-assembly of $\mathrm{TiO} 2$ nanoparticles was established through coordinance bonds with $\mathrm{OH}$ functional groups on the membrane surface, improving reversible deposition, hydrophilicity and flow and diminishing the irreversible fouling (Mansourpanah et al., 2009). $\mathrm{TiO}_{2}$-functionalized membranes may be obtained by several methods, but the sol-gel process is ubiquitous because it has many advantages such as purity, homogeneity, control over the microstructure, ease of processing, low temperature and low cost (Alphonse et al., 2010).

The advanced oxidation processes based on the photo-activity of semiconductor-type materials can be successfully used in wastewater treatment for destroying the persistent organic pollutants, resistant to biological degradation processes. $\mathrm{TiO}_{2}$ is the most attractive semiconductor because of its higher photocatalytic activity and can be used suspended into the reaction medium (slurry reactors) or immobilized as a film on solid material. A very promising method for solving problems concerning the photocatalyst separation from the reaction medium is to use the photocatalytic reactors in which $\mathrm{TiO}_{2}$ is immobilized on support. The immobilization of $\mathrm{TiO}_{2}$ onto various supporting materials has largely been carried out via physical or chemical route.

The application of photocatalysis in water and wastewater treatment has been well established, particularly in the degradation of organic compounds into simple mineral acids, carbon dioxide and water (Pera-Titus et al., 2004; Cassano and Alfano, 2000). Titanium dioxide $\left(\mathrm{TiO}_{2}\right)$, particularly in the anatase form is a photocatalyst under ultraviolet (UV) light. A reactor refers to $\mathrm{TiO}_{2}$ powder which is suspended in the water to be treated, while the immobilized catalyst reactor has $\mathrm{TiO}_{2}$ powder attached to a substrate which is immersed in the water to be treated. Immobilised $\mathrm{TiO}_{2}$ has become more popular due to the complications in the $\mathrm{TiO}_{2}$ suspension systems (Hoffmann et al., 1995).

The $\mathrm{TiO}_{2}$ immobilisation procedure developed not long ago can be used in determining a suitable immobilization procedure, particularly if economical and simple equipment is necessary. The overall performance of the $\mathrm{TiO}_{2}$ coating can be affected by various factors depending on the coating methods. In addition, it is also difficult to evaluate the photocatalytic efficiency of the coatings through photocatalytic activity (Augugliaro et al., 2008). Invariably, the $\mathrm{TiO}_{2}$ was immobilized using the sol-gel technique (Addamo et al., 2008). In this case, some problems are noted: decrease of surface area; potential loss of $\mathrm{TiO}_{2}$; decreased adsorption of organic substances on the $\mathrm{TiO}_{2}$ surface; mass transfer limitations. 
No polymeric support was considered to immobilise $\mathrm{TiO}_{2}$ since the polymeric material can undergo photo-oxidative degradation by illuminated $\mathrm{TiO}_{2}$ (Cassano and Alfano, 2000; Augugliaro et al., 2008).

Researchers have used photocatalytic oxidation to remove and destroy many types of organic pollutants. After photocatalysis was recognized to be a great oxidation mechanism, researchers began testing it on many different compounds, and in many different processes (Cassano and Alfano, 2000; Hoffmann et al., 1995; Addamo et al., 2008).

Phenolic compounds, a kind of priority pollutants, often occur in the aqueous environment due to their widespread use in many industrial processes such as the manufacture of plastics, dyes, drugs, antioxidants, and pesticides. Phenols, even at concentrations below 1 $\mathrm{lg} / \mathrm{L}$, can affect the taste and odor of the water (Pera-Titus et al., 2004). Therefore, the identification and monitoring of these compounds at trace level in drinking water and surface waters are imperative. Chlorophenols represent an important class of very common water pollutants. 4-chlorophenol is a toxic and non-biodegradable organic compound and can often be found in high quantity in the waste waters from various industrial sectors (Pera-Titus et al., 2004; Augugliaro et al., 2006). A severe toxicity of 4-chlorophenol requires the development of a simple, sensitive and reliable analytical method.

Among the advanced oxidation processes investigated in thelast decades, photocatalysis in the presence of an irradiated semiconductor has proven to be very effective in the field of environment remediation. The use of irradiation to initiate chemical reactions is the principle on which heterogeneous photocatalysis is based; infact, when a semiconductor oxide is irradiated with suitable light, excited electron-hole pairs result that can be applied in chemical processes to modify specific compounds.The main advantage of heterogeneous photocatalysis, when compared with the chemical methods, is that in most cases it is possible to obtain a complete mineralization of the toxic substrate even in the absence of added reagents.The radical mechanism of photocatalytic reactions, which involve fast attacks of strongly oxidant hydroxyl radicals, determines their un selective features.

Environmental applications of photocatalysis using $\mathrm{TiO}_{2}$ have attracted an enormous amount of research interest over the last three decades (Hoffmann et al., 1995; Linsebigler et al., 1995; Mills and Le Hunte, 1997; Stafford et al., 1996). It is well established that slurries of $\mathrm{TiO}_{2}$ illuminated with UV light can degrade to the point of mineralization almost any dissolved organic pollutant. Nevertheless, photocatalysis, particularly in aqueous media, has still not found widespread commercial implementation for environmental remediation. The main hurdle appears to be the cost, which is high enough to prevent the displacement of existing and competing technologies by photocatalysis. $\mathrm{TiO}_{2}$ research has progressed on multiple tiers, whereby the study of fundamental processes promotes material development, allowing no repeated uses that promise to play a larger and larger role in engineering sustainable technologies.

$\mathrm{TiO}_{2}$ is the most used semiconductor because of its higher photocatalytic activity, resistance to the photocorrosion process, absence of toxicity, biological immunity and the relatively 
low cost (Nikolaki et al., 2006; Han et al., 2009). $\mathrm{TiO}_{2}$ crystalline powder can be used suspended into a reaction medium (slurry reactors) or immobilized as a film on a carrier material. The anatase form of $\mathrm{TiO}_{2}$ is reported to give the best combination of photoactivity and photostability. An ideal photocatalyst for oxidation is characterized by the following attributes: photostability; chemically and biologically inert nature; availability and low cost; capability to adsorb reactants under efficient photonic activation (Bideau et al., 1995, Pozzo et al., 1997, Balasubramanian et al., 2004, Gaya and Abdullah, 2008, Siew-Teng Ong et al., 2009, Hanel et al., 2010). The support must have the following characteristics: (a) transparent to irradiation; (b) strong surface bonding with the $\mathrm{TiO}_{2}$ catalyst without negatively affecting the reactivity; (c) high specific surface area; (d) good absorption capability for organic compounds; (e) separability; (f) facilitating mass transfer processes and (g) chemically inert (Pozzo et al., 1997). As solid support, different materials were investigated: natural or synthetic fabrics, polymer membranes, activated carbon, quartz, glass, glass fiber, optical fibers, pumice stone, zeolites, aluminum, stainless steel, titanium metal or alloy, ceramics (including alumina, silica, zirconia, titania), red brick, white cement etc. (Bideau et al., 1995, Rachel et al., 2002, Balasubramanian et al., 2004, Kemmitt et al. 2004, Gunlazuardi and Lindu, 2005, Hunoh et al. 2005, Chen et al., 2006, Medina-Valtierra et al., 2006, Gaya and Abdullah, 2008, Lim et al., 2009, Siew-Teng Ong et al., 2009, Hanel et al., 2010, Zita et al., 2011).

The immobilization of $\mathrm{TiO}_{2}$ on different supporting materials has largely been carried out via a physical or chemical route: dip coating, porous material impregnation, sol-gel method, reactive thermal deposition, chemical vapor deposition, electron beam evaporation, spray pyrolysis, electrophoresis, electro-deposition (Rachel et al., 2002, Gunlazuardi and Lindu, 2005, Medina-Valtierra et al., 2006, Hanel et al., 2010, Zita et al., 2011).

The methods most commonly used for deposition of $\mathrm{TiO}_{2}$ on supports are sputtering and sol-gel dip-coating or spin-coating. Often the fixation of $\mathrm{TiO}_{2}$ on solid supports reduces its efficiency due to various reasons such as reduction of the active surface, a more difficult exchange with solution, introduction of ionic species etc. A degree of $60-70 \%$ reduction in performance is reported in aqueous systems for immobilized $\mathrm{TiO}_{2}$ as compared to the unsupported catalyst (Gaya and Abdullah, 2008), the best results being obtained by the immobilization of $\mathrm{TiO}_{2}$ on glass fiber (Rachel et al., 2002, Lim et al., 2009). The separation and/or removal technologies based on membrane and photocatalytic processes have a great potential for application in advanced wastewater treatment. Separation membranes have become essential parts of the human life because of their growing industrial applications in high technology such as biotechnology, nanotechnology and membrane based separation and purification processes. Available technologies to deal with chlorophenolic compounds include the advanced oxidation processes (AOPs) based on the formation of hydroxyl radicals with high oxidation potential.

The hybrid method consists in a photocatalytic procedure using a reactor equipped with $\mathrm{TiO}_{2}$-functionalized membrane (cylindrical shape) and high pressure mercury lamp for UV radiations generation, centrally and coaxially positioned. The $\mathrm{TiO}_{2}$-functionalized membranes have been obtained by sol-gel method synthesis of $\mathrm{TiO}_{2}$ (from 
tetrabutylortotitanate) as nanoparticles, formed directly in porous membrane regenerated cellulose type. Solutions of methyl, ethyl and propyl alcohols have been used as reaction medium. The experiments were performed at $30 \pm 2^{\circ} \mathrm{C}$ using synthetic solutions of $4-\mathrm{CP}$ (analytical grade reagent). The amount of hydrogen peroxide $(30 \% \mathrm{w} / \mathrm{w})$ used was calculated at 1.5 time $\mathrm{H} 2 \mathrm{O} 2 / 4-\mathrm{CP}$ stoichiometric ratio. The degradation process was studied by monitoring the organic substrate concentration changes function of reaction time using chemical oxygen demand analysis (COD).

The experimental data show the catalytic role of $\mathrm{TiO}_{2}$-functionalized membranes in the oxidation process. The oxidation is preceded by an adsorption process and the transfer of 4chlorophenol from the solution to the photocatalytic reaction zone through the functionalized membrane. Titanium dioxide, deposited on the membrane, acts as a photocatalyst in the presence of UV radiations leading to a higher efficiency of the oxidation process in a short reaction time. The catalytic activity of $\mathrm{TiO}_{2}$-functionalized membranes is influenced by the nature of the alcohol used in obtaining them. This can be explained by the crystallite size of $\mathrm{TiO}_{2}$ and their dispersion on membrane. However, at a higher reaction time, the determined solution COD values tend to increase, indicating that the $\mathrm{TiO}_{2}-$ functionalized membranes become unstable. This can be attributed to a partial solubilization process of membrane into reaction medium with a strong oxidizing potential.

The presence of phenol and phenolic derivatives in water induces toxicity, persistence and bioaccumulation in plant and animal organisms and is a risk factor for human health. The technologies of separation and/or removal of phenolic derivatives based on membrane and photocatalytic processes play an important role.

Available technologies to deal with phenolic compounds include the advanced oxidation processes, based on the formation of very active hydroxyl radicals, which react quickly with the organic contaminant. Among the AOPs, the photocatalytic process is one of the most attractive methods because the reagent components are easy to handle and environmentally benign.

\section{Wastewater decontamination by processes of absorption}

Rapid development of industry and society led to serious environmental problems such as contamination of groundwater and surface chemical treatment with organic compounds coming from agriculture (pesticides, herbicides, other.) or inorganic compounds in industry (pigments, heavy metals, etc.)

A method used for the wastewater decontamination is the contaminants absorption on the catalyst surface. The most known adsorbent substances cleansing practice are: activated carbon, silica gel, discolored soils, molecular sieves, cotton fibers etc.

After the manner in which the contact is realized between wastewater and adsorbent is distinguished static and dynamic adsorption. In the first case finely adsorbent divided is stirred with water and after a time it's separated by decantation or filtration. In the dynamic adsorption case, wastewater passes through a fixed, mobile or a fluidized absorbent layer with a continuous flow. 
Another alternative to the wastewater treatment is the use of technologies based on magnetic nanomaterials $\mathrm{AB}_{2} \mathrm{O}_{4}$ type $\left(\mathrm{A}=\mathrm{Co}, \mathrm{Ni}, \mathrm{Cu}, \mathrm{Zn}, \mathrm{B}=\mathrm{Fe}^{3+}\right)$ used as catalysts for degradation of organic compounds or absorbents to retain the surface pollutants heavy metals (mercury, arsenic, lead and others). Their importance and complexity led to research programs development on magnetic materials, with new or improved properties in last decades. These properties are dependent on chemical composition and microstructural characteristics, which can be controlled in the fabrication and synthesis processes.

These materials must have a relatively high surface area, a smaller particle size, and porous structure. In particular, the magnetic properties of the powders makes them to be easily recovered by magnetic separation technology after adsorption or regeneration, which overcomes the disadvantage of separation difficulty of common powdered adsorbents $(\mathrm{Qu}$, et.al, 2008).

Challenges in synthesis of nanostructured catalysts are that many reactions employ mixed catalysts consisting of different oxide metals, and that the function of active centers is not only determined by the constituent atoms but also by the surrounding crystal or surface structures; it is thus necessary to accurately control the synthesis of nanostructured catalysts (Rickerby, et.al, 2007).

Magnetite nanoparticles have highest saturation magnetization of $90 \mathrm{emu} / \mathrm{g}$ among iron oxides. Therefore, magnetite nanoparticles can be used to adsorb arsenic ions followed by magnetic decantation. Other iron oxides and hydroxides have been reported to have arsenic ability (Hai, et. al, 2009). Oxidation resistance is an important factor for arsenic removal under atmospheric conditions.

By diverse synthesis methods (hydrothermal, ultrasonic hydrothermal, sol-gel, coprecipitation and other), was obtained ferrite nanomaterials derived from magnetite (FeO, $\left.\mathrm{Fe}_{2} \mathrm{O}_{3}\right)$ substituting the $\mathrm{Fe}^{2+}$ ion in different concentrations $(0.5,0.8,1,1.2,1.5)$ with $\mathrm{Co}^{2+}, \mathrm{Cu}^{2+}$, $\mathrm{Ni}^{2+}, \mathrm{Zn}^{2+}$ ions (Vlazan, 2010; Fannin, et.al, 2011).

\section{Membrane oxidative processes in water treatment}

This topic gives an overview of the hybrid photocatalysis-membrane processes and their possible applications in water and wastewater treatment. Different configurations of photocatalytic membrane reactors (PMRs) are described and characterized. They include PMRs with photocatalyst immobilized on/in the membrane and reactors with catalyst in suspension. The advantages and disadvantages of the hybrid photocatalysis-membrane processes in terms of permeate flow, membrane fouling and permeate quality are discussed. Moreover, a short introduction to the heterogeneous photocatalysis and membrane processes as unit operations is given.

The detailed mechanism of the photocatalytic oxidation of organic compounds in water has been discussed widely in the literature and will be presented here in brief only. The overall process can be divided into the following steps. 
1. Diffusion of reactants from the bulk liquid through a boundary layer to the solutioncatalyst interface (external mass transfer).

2. Inter-and/or intra-particle diffusion of reactants to the active surface sites of the catalyst (internal mass transfer).

3. Adsorption of at least one of the reactants.

4. Reactions in the adsorbed phase.

5. Desorption of the product(s).

6. Removal of the products from the interface of the bulk solution.

A photocatalyst should be characterized by: (I) high activity, (II) resistance to poisoning and stability in prolonged at elevated temperatures, (III) mechanical stability and resistance to attrition, (IV) non-selectivity in most cases, and (V) physical and chemical stability under various conditions. Moreover, it is desirable for the photocatalyst to be able to use not only $\mathrm{UV}$, but also visible light and to be inexpensive. Different semiconducting materials, such as oxides ( $\mathrm{TiO}_{2}, \mathrm{ZnO}, \mathrm{CeO}_{2}, \mathrm{ZrO}_{2}, \mathrm{WO}_{3}, \mathrm{~V}_{2} \mathrm{O}_{5}, \mathrm{Fe}_{2} \mathrm{O}_{3}$, etc.) and sulfides (CdS, $\mathrm{ZnS}$, etc.) have been used as photocatalysts.

Recently, numerous investigations have been focused on different modifications of $\mathrm{TiO}_{2}$ in order to improve its activity under UV irradiation or to reduce the band gap energy so that it is able to utilize the visible light. The best photocatalytic performances with maximum quantum yields have been always obtained with $\mathrm{TiO}_{2}$. Anatase is the most active allotropic form of $\mathrm{TiO}_{2}$ among the various ones available. Unfortunately, due to a wide band gap (about $3.2 \mathrm{eV}$ ), $\mathrm{TiO}_{2}$ is inactive under visible light.

The most important operating parameters which affect the efficiency of the photocatalytic oxidation process can be summarized as follows: reactor design; light wavelength and intensity; loading of the photocatalyst; initial concentration of the reactant; temperature; $\mathrm{pH}$ of reaction medium; oxygen content; the presence of inorganic ions (Mozia, 2005; Gogate and Pandit, 2004; Hermann, 2006).The photocatalytic reactors can be divided into two main groups:

i. Reactors with $\mathrm{TiO}_{2}$ suspended in the reaction mixture: in the case of reactors with $\mathrm{TiO}_{2}$ suspended in the reaction mixture (I), the photocatalyst particles have to be separated from the treated water after the oxidation process.

ii. Reactors with $\mathrm{TiO}_{2}$ fixed on a carrier material (glass, quartz, stainless steel, pumice stone, titanium metal, zeolites, pillared clays, membranes etc.).

A very promising method for solving problems concerning separation of the photocatalyst as well as products and by-products of photo-oxidation process from the reaction mixture is application of photocatalytic membrane reactors (PMRs). PMRs are hybrid reactors in which photo-catalysis is coupled with a membrane process. The membrane would play both the role of a simple barrier for the photocatalyst and of a selective barrier for the molecules to be degraded. Membrane processes are separation techniques which are widely applied in various sectors of industry including food, chemical and petrochemical, pharmaceutical, 
cosmetics and electronic industries, water desalination, water and wastewater treatment and many others. The main advantages of membrane processes are: low energy consumption; low chemicals consumption; production of water of stable quality almost independent on the quality of the treated water; automatic control and steady operation allowing performance of a continuous operation; low maintenance costs; easy scale up by simple connecting of additional membrane modules

Synthetic membranes may be: organic or inorganic materials; homogeneous or heterogeneous; symmetrical or asymmetrical; porous or dense; electrically neutral or charged.

In this sense, the driving forces are: pressure difference; concentration difference; partial pressure difference or electrical potential difference.

Most of the PMRs described in the literature combine photo-catalysis with pressure driven membrane processes such as:

- $\quad$ Micro-Filtration (MF)

- Ultra-Filtration (UF)

- Nano-Filtration (NF)

- Dialysis

- $\quad$ Pervaporation (PV)

- $\quad$ Direct Contact Membrane Distillation (DCMD)

Hybrid photocatalysis-membrane processes are conducted in the installations often called "photocatalytic membrane reactors". However, in the literature, other names for these configuration scan be also found, including "membrane chemical reactor" (MCR), "membrane reactor", "membrane photoreactor", or, more specific, "submerged membrane photocatalysis reactor" and "photocatalysis-ultrafiltration reactor"(PUR). For the hybridization of photocatalysis with membrane process it will be useful to apply a general term of "photocatalytic membrane reactor".

Photocatalytic membrane reactors design show in figure $2(a, b)$.

Photocatalytic membranes for the PMRs can be prepared from different materials and indifferent ways. Figure 3 presents two possible types of asymmetric photocatalytic membranes (Bosc et al., 2005). In the first case, photoactive separation layer is deposited on a non-photoactive porous support (Fig. 3a) the photoactive layer, being also the separation layer (skin) is formed on a porous non-photoactive support. In the second case, a nonphotoactive separation layer is deposited on a photoactive porous support (Fig. 3b) the separation layer is non-photoactive and is deposited on a porous active support.

The main advantage of PMRs with photocatalytic membranes is that this configuration allows one to minimize the mass transfer resistances between the bulk of the fluid and the semiconductor surface. 


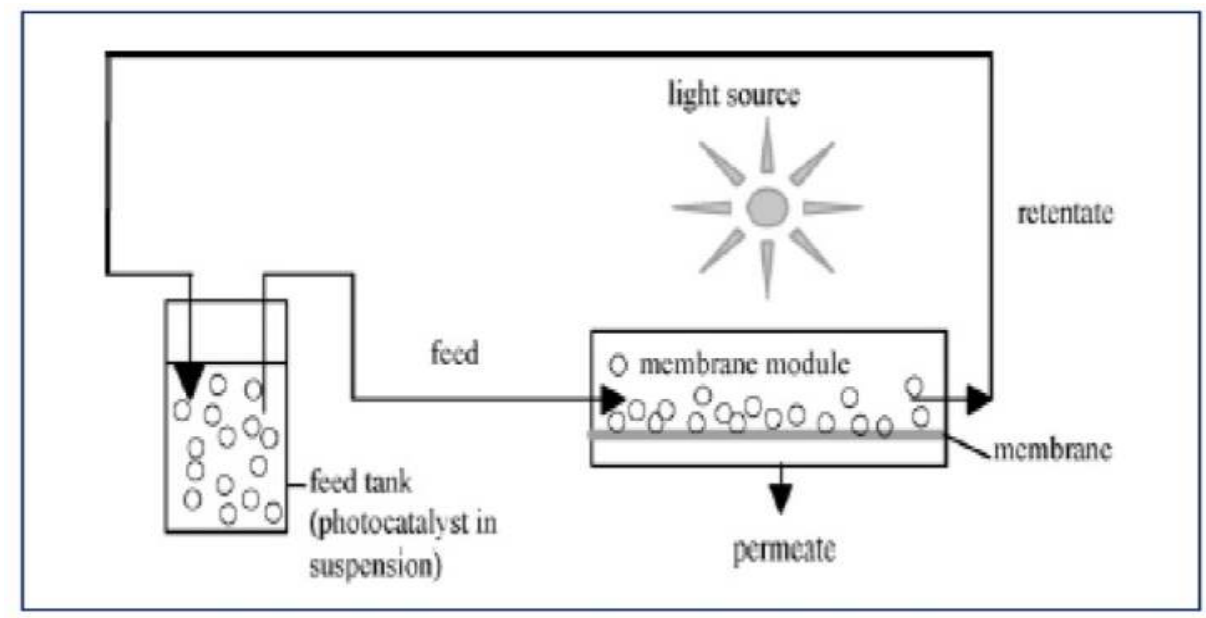

(a)

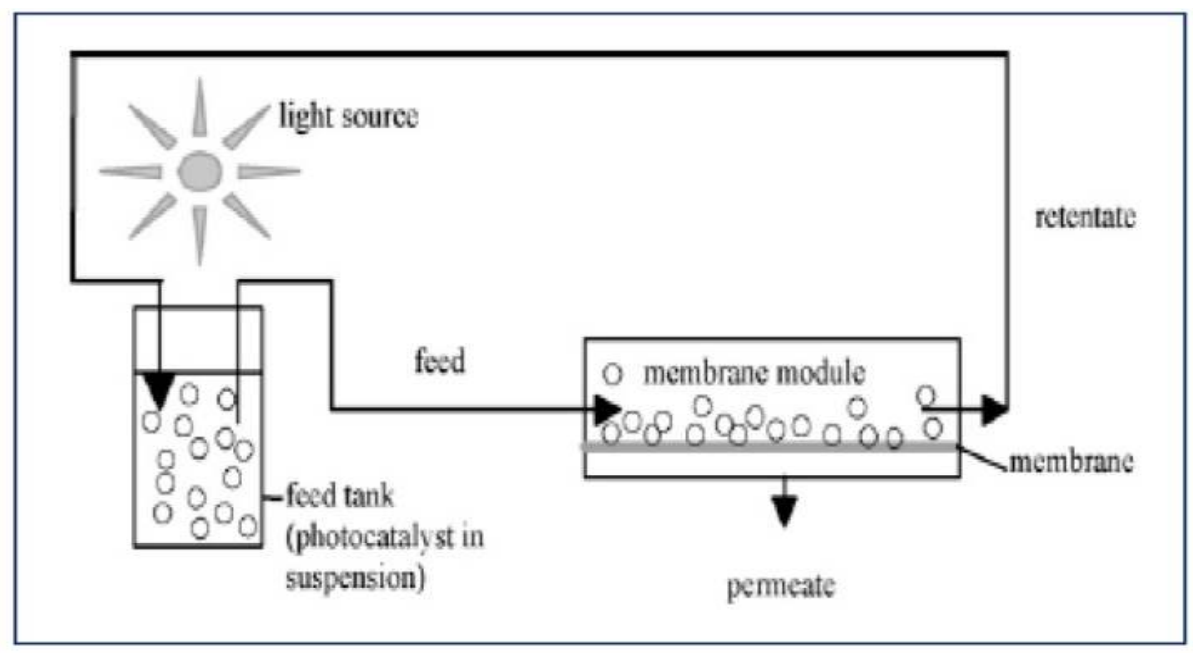

(b)

Figure 2. a. PMR utilizing photo-catalyst in suspension: irradiation of the membrane module (Mozia S., 2010), b. PMR utilizing photo-catalyst in suspension: irradiation of the feed tank (Mozia S., 2010) 

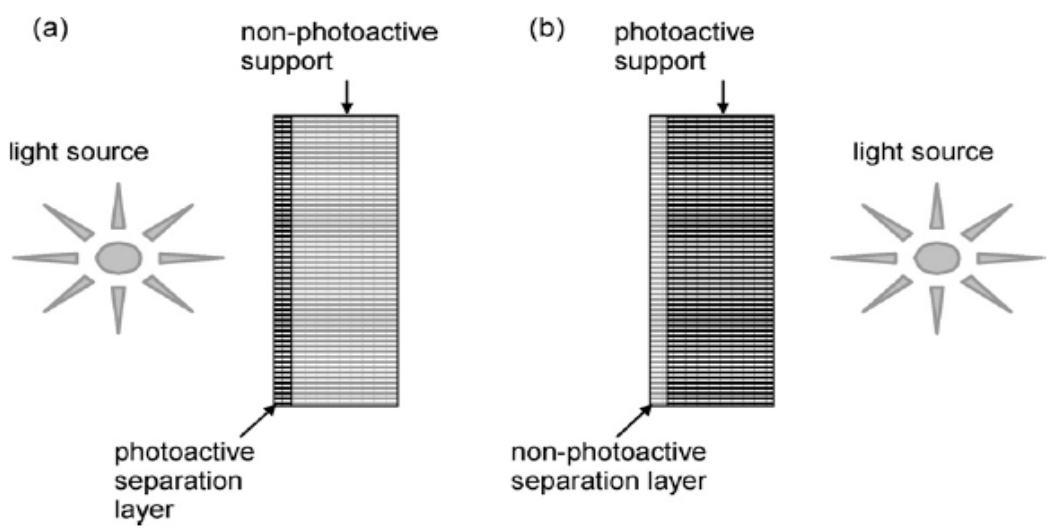

Figure 3. Asymmetric photocatalytic membranes (Bosc et al., 2005)

\section{Conclusion}

Choosing the most suitable method of wastewater treatment studies require both increasing the effectiveness and economic efficiency (operating and investment costs).

Advanced oxidation processes (AOPs) are good alternatives for removal the toxic compunds from wastewater. The AOPs can be successfully used in wastewater treatment to degrade the persistent organic pollutants, the oxidation process being determined by the very high oxidative potential of the $\mathrm{HO}$ radicals generated into the reaction medium by different mechanisms. AOPs can be applied to fully or partially oxidize pollutants, usually using a combination of oxidants. Photo-chemical and photo-catalytic advanced oxidation processes including $\mathrm{UV} / \mathrm{H}_{2} \mathrm{O}_{2}, \mathrm{UV} / \mathrm{O}_{3}, \mathrm{UV} / \mathrm{H}_{2} \mathrm{O}_{2} / \mathrm{O}_{3}, \mathrm{UV} / \mathrm{H}_{2} \mathrm{O}_{2} / \mathrm{Fe}^{2+}\left(\mathrm{Fe}^{3+}\right), \mathrm{UV} / \mathrm{TiO}_{2}$ and $\mathrm{UV} / \mathrm{H}_{2} \mathrm{O}_{2} / \mathrm{TiO}_{2}$ can be used for oxidative degradation of organic contaminants. A complete mineralization of the organic pollutants is not necessary, being more worthwhile to transform them into biodegradable aliphatic carboxylic acids followed by a biological process. The efficiency of the various AOPs depend both on the rate of generation of the free radicals and the extent of contact between the radicals and the organic compound.

Photocatalytic oxidation in water treatment has proved its efficiency at many pilot-scale applications. However, wide marketing of commercially available solar detoxification systems is obstructed by the general market situation: a new water treatment procedure has an opportunity to be implemented only when its cost is at least two-fold lower than the cost of a procedure currently in use. Photocatalysis, also called the "green" technology, represents one of the main challenges in the field of treatment and decontamination systems, especially for water and air. Its operating principle is based on the simultaneous action of the light and a catalyst (semi-conductor), which allows for pollutant molecules to be destroyed without damaging the surrounding environment.

In recent years, applications to environmental remediation have been one of the most active subjects in photocatalysis. 


\section{Author details}

Adina Elena Segneanu, Carmen Lazau, Paula Sfirloaga, Paulina Vlazan,

Cornelia Bandas and Ioan Grozescu*

National Institute for Research and development in Electrochemistry and Condensed Matter-

INCEMC Timisoara, Romania

Cristina Orbeci

Politehnica University Bucuresti, Romania

\section{References}

Addamo, M., Augugliaro, V., Di Paola, A., García-López, E., Loddo, V., Marcì, G., Palmisano, L., (2008), Photocatalytic thin films of $\mathrm{TiO}_{2}$ formed by a sol-gel process using titaniumtetraisopropoxide as the precursor, Thin Solid Films 516, pp. 3802-3807.

Ahmed, S., Rasul, M. G., Martens, W. N., Brown R., Hashib, M. A., ( 2010), “Heterogeneous photocatalytic degradation of phenols in wastewater: A review on current status and developments", Desalination, 261(1-2), pp. 3-18.

Alexy, R., Kümpel, T., Kümmerer, K., (2004), Assessment of degradation of 18 antibiotics in the Closed Bottle Test. Chemosphere 57, 505-512.

Alphonse, P., Varghese A., Tendero, C., (2010), "Stable hydrosols for $\mathrm{TiO}_{2}$ coatings", Journal of Sol-Gel Science and Technology, 56(3), 250-263.

Andreozzi R.; Caprio V.; Insola A.; Marotta R. (1999), Advanced oxidation processes (AOP) for water purification and recovery, Catalysis Today, 53 (1), 51-59

Anita Rachel, Machiraju Subrahmanyam, Pierre Boule, (2002), Comparison of photocatalytic efficiencies of $\mathrm{TiO}_{2}$ in suspended and immobilised form for the photocatalytic degradation of nitrobenzenesulfonic acids, Applied Catalysis B: Environmental 37(4), 301308.

Arslan-Alaton, I., Caglayan, A.E., (2006), Toxicity and biodegradability assessment of raw and ozonated procaine penicillin G formulation effluent. Ecotox. Environ. Safe. 63, 131140.

Arslan-Alaton, I., Dogruel, S., Baykal, E., Gerone, G., (2004), Combined chemical and biological oxidation of penicillin formulation effluent. J. Environ. Manag. 73, 155-163.

Augugliaro, V., Litter, M., Palmisano, L., Soria, J., (2006), The combination of heterogeneous photocatalysis with chemical and physical operations: A tool for improving the photoprocess performance, Journal of Photochemistry and Photobiology C: Photochemistry Reviews 7, 127-144.

Ay, F., Kargi, F., (2010), Advanced oxidation of amoxicillin by Fenton' reagent treatment. J.Hazard.Mater. 179, 622-627.

${ }^{*}$ Corresponding Author 
Balasubramanian G., Dionysiou D.D., Suidan M.T., Baudin I., Laîné J.M., (2004), Evaluating the activities of immobilized $\mathrm{TiO}_{2}$ powder films for the photocatalytic degradation of organic contaminants in water. Applied Catalysis B: Environmental, 47(2), 73-84.

Bideau, M., Claudel, B., Dubien, C., Faure, L., Kazouan H., (1995), On the “immobilization" of titanium dioxide in the photocatalytic oxidation of spent waters, Journal of Photochemistry \& Photobiology A: Chemistry, 91(2), 137-144.

Bosc, F., Ayral, A., Guizard, C., (2005), Mesoporous Anatase Coatings for Coupling Membrane Separation and Photocatalyzed Reactions" J. Membr. Sci. 265, 13-19.

Bound, J.P., Voulvoulis, N., (2004), Pharmaceuticals in the aquatic environment - a comparison of risk assessment strategies. Chemosphere 56, 1143-1155.

Byrappa, K., Rai, K.M.L., Yoshimura, M. (2002), "Hydrothermal preparation of $\mathrm{TiO}_{2}$ and photocatalytic degradation of hexachloro cyclohexane and dichlorodiphenyl trichloromethane", Journal of Environmental Science and Technology, 21, pp 1085-1090;

Cassano, A. E., Alfano, O. M. (2000) "Reaction Engineering of Suspended Solid Heterogeneous Photocatalytic Reactors", Catalysis Today, 58(2-3), pp. 167-197.

Carp, O., Huisman, C.L., Reller, A., (2004), Photoinduced reactivity of titanium dioxide, Prog. Solid State Chem. 32(1-2), 33-177.

Chakinala, A.G., Gogate, P.R., Burgess, A.E., Bremner, D.H., (2009), Industrial wastewater treatment using hydrodynamic cavitation and heterogeneous advanced Fenton processing. Chemical Engineering Journal, 152, 498-502.

Chen S.Z, Zhang P.Y, Zhu W.P., Chen L, Sheng-Ming Xu, (2006), Deactivation of $\mathrm{TiO}_{2}$ photocatalytic films loaded on aluminium: XPS and AFM analyses, Appl. Surf. Sci. 252 (20), 7532-7538.

Chin, S. S., Chiang, K., Fane, A. G., (2006), “The stability of polymeric membranes in a $\mathrm{TiO}_{2}$ photocatalysis process", Journal of Membrane Science, 275(1-2), pp. 202-211.

Daneshvar N., Salari D., Khataee A.R., (2003), Photocatalytic degradation of azo dye acid red 14 in water: investigation of the effect of operational parameters, Journal of Photochemistry and Photobiology A: Chemistry, 157 111-116;

Daneshvar N., Aber S., Seyed Dorraji M. S., Khataee A. R., Rasoulifard M. H., (2007), Preparation and Investigation of Photocatalytic Properties of ZnO Nanocrystals: Effect of Operational Parameters and Kinetic Study, World Academy of Science, Engineering and Technology 29;

Daneshvar N., D. Salari, A.R. Khataee, (2003), Photocatalytic degradation of azo dye acid red 14 in water: investigation of the effect of operational parameters, Journal of Photochemistry and Photobiology A: Chemistry 157, 111-116.

De Laat J., Truong Le G., Legube B., (2004), A comparative study of the effects of chloride, sulfate and nitrate ions on the rates of decomposition of $\mathrm{H}_{2} \mathrm{O}_{2}$ and organic compounds by $\mathrm{Fe}(\mathrm{II}) / \mathrm{H}_{2} \mathrm{O}_{2}$ and $\mathrm{Fe}(\mathrm{III}) / \mathrm{H}_{2} \mathrm{O}_{2}$. Chemosphere, 55(5):715-23.

Du Y., Zhou M., Lei L., (2006), Role of the intermediates in the degradation of phenolic compounds by Fenton-like process, Journal of Hazardous Materials, 136, 859-865. 
Duarte F., Madeira L.M., (2010), Fenton and Photo-Fenton-Like Degradation of a Textile Dye by Heterogeneous Process with Fe/ZSM-5 Zeolite, Separation Science and Technology, 45, 1512-1520.

Elmolla, E., Chaudhuri, M., (2009), Degradation of the antibiotics amoxicillin, ampicillin and cloxacillin in aqueous solution by photo-Fenton process. J. Hazard. Mater. 172, 14761481.

Esplugas, S., Gimenez, J., Contreras, S., Pascual, E., Rodriguez M., (2002), Comparison of different advanced oxidation processes for phenol degradation, Water Res., 36, p. 10341042

Fang Han, Venkata Subba Rao Kambala, Madapusi Srinivasan, Dharmarajan Rajarathnam, Ravi Naidu, (2009), Tailored titanium dioxide photocatalysts for the degradation of organic dyes in wastewater treatment: A review. Applied Catalysis A, General, 359 (1-2), 2009, 25-40.

Fannin P.C., Marin C.N., Malaescu I., Stefu N., Vlăzan P., Novaconi S., Popescu S., (2011), Effect of the concentration of precursors on the microwave absorbent properties of Zn/Fe oxide nanopowders; Journal of Nanoparticle Research; 13, 311-319.

Feng J., Hu X., Yue P. L., (2005), Discoloration and mineralization of Orange II by using a bentonite clay-based Fe nanocomposite film as a heterogeneous photo-Fenton catalyst, Water Research, 39, 89-96.

Gao, Y., Liu, H., (2005), Preparation and catalytic property study of a novel kind of suspended photocatalyst of $\mathrm{TiO}_{2}$-activated carbon immobilized on silicone rubber film, Mater. Chem. Phys. 92(2-3), 604-608.

Gayaa U. I., Abdullaha A. H., (2008), Heterogeneous photocatalytic degradation of organic contaminants over titanium dioxide: A review of fundamentals, progress and problems, Journal of Photochemistry and Photobiology C: Photochemistry Reviews 9, 1-12.

Getoff N., (2001), Comparison of radiation and photoinduced degradation of pollutants in water: synergistic effect of $\mathrm{O} 2, \mathrm{O} 3$ and TiO2. A Short Review, Research on Chemical Intermediates, Vol. 27, Numbers 4-5, 343-358.

Li Puma G., Bonob A., Krishnaiah D., Collin J.G.,(2008) Preparation of titanium dioxide photocatalyst loaded onto activated carbon support using chemical vapor deposition: A review paper, Journal of Hazardous Materials 157. 209-219.

Gogate P. R., Pandit A. B., (2004), A review of imperative technologies for wastewater treatment II: hybrid methods, Advances in Environmental Research, 8, 553-597.

Guillard C.; Disdier J.; Herrmann J.-M.; Lehaut C.; Chopin T.; Malato S.;Blanco J., 1999, Comparison of various titania samples of industrial origin in the solar photocatalytic detoxification of water containing 4-chlorophenol, Catalysis Today, 54, (2,-3), 217-228.

Hänel, A., Moren, P., Zaleska, A., Hupka, J. (2010), Photocatalytic activity of TiOzimmobilized on glass beads, Physicochem. Probl. Miner. Process. 45, 49-56

Hansen H. K., Nunez P., Raboz D., Schippacasse I., Grandon R., (2007), Electrocoagulation in wastewater containing arsenic: Comparing different process designs, ScienceDirect, Electrochimica Acta 52, 3464-3470. 
Hai N. H., Phu N. D., 25 (2009), Arsenic removal from water by magnetic $\mathrm{Fe}_{1-\mathrm{x}} \mathrm{Cox}_{\mathrm{Fe}} \mathrm{Fe}_{4}$ and $\mathrm{Fe}_{-y} \mathrm{Ni}_{\mathrm{y}} \mathrm{Fe}_{2} \mathrm{O}_{4}$ nanoparticles; VNU Journal of Science, Mathematics - Physics 15-19.

He J., Ma W., Song W., Zhao J., Qian X., Zhang S., Yu J. C., (2005), Photoreaction of aromatic compounds at a-FeOOH/ $\mathrm{H}_{2} \mathrm{O}$ interface in the presence of $\mathrm{H}_{2} \mathrm{O}_{2}$ : evidence for organicgoethite surface complex formation, Water Research, 39, 119-128.

Hepel M., Hazelton S., (2005), Photoelectrocatalytic degradation of diazo dyes on nanostructured $\mathrm{WO}_{3}$ electrodes, Electrochimica Acta 50. 5278-5291.

Hoffmann, M. R., Martin, S. T., Choi, W., Bahnemann, D. W., (1995) „Environmental Applications of Semiconductor Photocatalysis", Chemical Reviews, 95, pp. 69-96.

Hu, K.H., Yong Kui Cai Y.K., Li S., (2011), Photocatalytic Degradation of Methylene Blue on MoS2/TiO2, Nanocomposite, Advanced Materials Research, Volumes 197 - 198.

Hua, Zi-Le, Shi, Jian-Lin, Zhang, Wen-Hua, Huang, Wei-Min, (2002), Direct synthesis and characterization of Ti-containing mesoporous silica thin films, Materials Letters 53(4-5), 299-304.

Kaniou, S., Pitarakis, K., Barlagianni, I., Poulios, I., (2005), Photocatalytic oxidation of sulfamethazine. Chemosphere 60, 372-380.

Jarnuzi Gunlazuardi, Winarti Andayani Lindu, (2005), Photocatalytic degradation of pentachlorophenol in aqueous solution employing immobilized $\mathrm{TiO}_{2}$ supported on titanium metal, Journal of Photochemistry and Photobiology A: Chemistry, 173(1), 51-55.

Jiří Zita, Josef Krýsa, Urh Černigoj, Urška Lavrenčič-Štangar, Jaromír Jirkovský, Jiří Rathouský, (2011), Photocatalytic properties of different $\mathrm{TiO}_{2}$ thin films of various porosity and titania loading, Catalysis Today, 161 (1), 29-34.

João Rocha, Artur Ferreira, Zhi Lin, Michael W. Anderson, (1998), Synthesis of microporous titanosilicate ETS-10 from $\mathrm{TiCl}_{3}$ and $\mathrm{TiO}_{2}$ : a comprehensive study, Micropor. Mesopor. Mater, 23(5-6), 253-263.

Jorge Medina-Valtierra, Manuel Sánchez-Cárdenas, Claudio Frausto-Reyes, Sergio Calixto, (2006), Formation of smooth and rough $\mathrm{TiO}_{2}$ thin films on fiberglass by sol-gel method, J. Mex. Chem. Soc., 50(1), 8-13.

Kavitha V., Palanivelu K., (2004), The role of ferrous ion in Fenton and photo-Fenton processes for the degradation of phenol, Chemosphere, 55, 1235-1243.

Kakuta S., Abe T., (2009), Photocatalysis for water oxidation by Fe2O3 nanoparticles embedded in clay compound: correlation between its polymorphs and their photocatalytic activities, Journal of Materials Science, Vol. 44, Number 11 2890-2898.

Khelifa A., Moulay S., Naceur A.W., (2005), Treatment of metal finishing effluents by the electroflotation technique, Desalination 181, 27-33.

Kondo Y., Fujihara S., (2011), Solvothermal Synthesis of $\mathrm{WO}_{3}$ Photocatalysts and their Enhanced Activity, Key Engineering Materials (Volume 485) 283-286.

Hu K.H., Yong Kui Cai , Sai Li, (2011), Photocatalytic Degradation of Methylene Blue on $\mathrm{MoS}_{2} / \mathrm{TiO}_{2}$ Nanocomposite, Advanced Materials Research , vol 197 - 198, 996-999;

Kümmerer, K., (2009), Antibiotics in the aquatic environment - A review - Part I. Chemosphere 75, 417-434. 
Kwon, B. G., Lee, D. S., Kang, N., Yoon, J., (1999), Characteristics of p-chlorophenol oxidation by Fenton's reagent.Water Res. 33 (9), 2110-2118.

Lazau C., Ratiu C., Orha C., R. Pode, F. Manea, (2011), Photocatalytic activity of undoped and Ag-doped $\mathrm{TiO}_{2}$-supported zeolite for humic acid degradation and mineralization, Materials Research Bulletin 46, 11, Pages 1916-1921.

Leland J. K., Bard A. J., (1987), Photochemistry of colloidal semiconducting iron oxide polymorphs, Journal of Physical Chemistry, 91, 5076-5083.

Li Puma G., Bonob A, Krishnaiah D., Collin J.G., (2008), Preparation of titanium dioxide photocatalyst loaded onto activated carbon support using chemical vapor deposition: A review paper, Journal of Hazardous Materials, 157 209-219.

Li, J.-H., Xu, Y.-Y., Zhu, L.-P., Wang, J.-H., Du, and C.-H., (2009), Fabrication and characterization of a novel $\mathrm{TiO}_{2}$ nanoparticle self-assembly membrane with improved fouling resistance, Journal of Membrane Science, 326(2), pp. 659-666.

Li, X.Y., Cui, Y.H., Feng, Y.J., Xie, Z.M., Gu, J.D., (2005), Reaction pathways and mechanisms of the electrochemical degradation of phenol on different electrodes. Water Res. 39, 1972-1981.

Lim, L. L. P., Lynch, R. J., In, S. I. (2009), Comparison of simple and economical photocatalyst immobilisation procedures, Applied Catalysis A: General, 365(2): 214221.

Liu Xinsheng. Kerry Thomas. J., (1996), Synthesis of microporous titanosilicates ETS-10 and ETS-4 using solid $\mathrm{TiO}_{2}$ as the source of titanium, Chem. Commun., 12, 1435-1436.

Lopez T., M. Alvarez, F. Tzompantzi, M. Picquart, Photocatalytic degradation of 2,4dichlorophenoxiacetic acid and 2,4,6-trichlorophenol with $\mathrm{ZrO} 2$ and $\mathrm{Mn} / \mathrm{ZrO} 2$ sol-gel materials, J Sol-Gel Sci Techn (2006) 37: 207-211.

Lu M. C., Chen J. N., Chang C. P., (1997), Effect of inorganic ions on the oxidation of dichlorvos insecticide with Fenton's reagent. Chemosphere, 35(10), 2285-2293.

Mansourpanah, Y., Madaeni, S. S., Rahimpour, A., Farhadian, A., Taheri, A. H. (2009), Formation of appropiate sites on nanofiltration membrane surface for binding $\mathrm{TiO}_{2}$ photo-catalyst: Performance, characterization and fouling-resistant capability", Journal of Membrane Science, 330(1-2), pp. 297-306.

Molinari, R. , Mungari, M., Drioli, E., Di Paola, A., Loddo, V., Palmisano L., Schiavello,M., (2000), Study on a photocatalytic membrane reactor for water purification", Catalysis Today, 55(1-2), pp. 71-78.

Moura F. C. C., Araujo M. H., Costa R. C. C., Fabris J. D., Ardisson J. D., Macedo W. A. A., Lago R. M., (2005), Efficient use of Fe metal as an electron transfer agent in a heterogeneous Fenton system based on $\mathrm{Fe}^{0} / \mathrm{Fe}_{3} \mathrm{O}_{4}$ composites, Chemosphere, 60, 11181123.

Moura F. C. C., Oliveira G. C., Araujo M. H., Ardisson J. D., Macedo W. A. A., Lago R. M., Highly reactive species formed by interface reaction between Fe-iron oxides particles: An efficient electron transfer system for environmental applications, Applied Catalysis A: General, 307, (2006), 195-204. 
Mozia, S., (2010), "Photocatalytic membrane reactors (PMRs) in water and wastewater treatment. A review", Separation and Purification Technology, 73(2), pp. 71-91.

Munoz I., Rieradevall J., Torrades F., Peral J., Domenech X., (2005), Environmental Assessment of Different Solar Driven Advanced Oxidation Processes", Sol. Energy, 79, p. 369.

Munter R., (2001), Advanced Oxidation Processes - Current Status and Prospects, Proc. Estonian Acad. Sci. Chem. 50(2) p. 59.

Nie Y., Hu C., Zhou L., Qu J., (2008), An efficient electron transfer at the $\mathrm{Fe}^{0}$ /iron oxide interface for the photoassisted degradation of pollutants with $\mathrm{H}_{2} \mathrm{O}_{2}$, Applied Catalysis B; Environmental, 82, 151-156.

Nikolaki, M. D., Malamis, D., Poulopoulos, S. G., Philippopoulos, C. J. (2006), Photocatalytical degradation of 1,3-dichloro-2-propanol aqueous solutions by using an immobilized $\mathrm{TiO}_{2}$ photoreactor, Journal of Hazardous Materials 2006, 137(2), 1189-1196.

Oh S.H., Kim J.S., Chung J.S., Kim E.J., Hahn S. H., (2005), Crystallization and Photoactivity of TiO2 Films Formed on Soda Lime Glass by a Sol-Gel Dip-Coating Process, Chem. Eng. Comm. 192 (3), 327-335.

Ong S.T., Lee C.K., Zainal Z., Keng P.S. Ha S.T., (2009), Photocatalytic degradation of basic and reactive dyes in both single and binary systems using immobilized $\mathrm{TiO}_{2}$, Journal of Fundamental Sciences, 5(2), 88-93.

Orbeci, C., Untea, I., Kopsiaftis, G., (2008), The influence of inorganic species on oxidative degradation of 4-chlorphenol by photo-Fenton type process, Revista de Chimie 59(9), 952955.

Orbeci, C., Untea, I., Dancila, M., Stefan, D.S., (2010), Kinetics considerations concerning the oxidative degradation by photo-Fenton process of some antibiotics. Environ. Eng. Manage. J., 9, 1-5.

Ortiz de la Plata G. B., Alfano O. M., Cassano A. E., (2010), Decomposition of 2-chlorophenol employing goethite as Fenton catalyst. I. Proposal of a feasible, combined reaction scheme of heterogeneous and homogeneous reactions, Applied Catalysis B: Environmental, 95, 1-13.

Papp J., Shen H.S., Kershaw R, Dwight K., Wold A., (1993), Titanium(IV) Oxide Photocatalysts with Palladium, Chem. Mater. 5, 284;

Pera-Titus M., Garcia-Molina V., Banos M. A., Gimenez J., Esplugas S., (2004), Degradation of chlorophenols by means of advanced oxidation processes: a general review, Applied Catalysis B: Environmental, 47, 219-256.

Pignatello, J.J., (1992), Dark and photoassisted $\mathrm{Fe}^{3+}$ catalyzed degradation of chlorophenoxy herbicides by hydrogen peroxide, Environ.Sci.Technol. 26, 944-951.

Qu J., (2008), Research progress of novel adsorption processes in water purification: A review; Journal of Environmental Sciences 201-13.

Ratiu C., Manea , F. Lazau, C., Grozescu, I. Radovan C., Schoonman, J., Electrochemical oxidation of p-aminophenol from water with boron-doped diamond anodes and assisted photocatalytically by $\mathrm{TiO}_{2}$-supported zeolite, Desalination 260 (2010) 51-56. 
Ratiu C., Manea , F. Lazau, C., Orha, C., Burtica, G., Grozescu, I., Schoonman, J., Photocatalytically-assisted electrochemical degradation of p-aminophenol in aqueous solutions using zeolite-supported $\mathrm{TiO}_{2}$ catalyst, Chemical Papers 65 (3) 289-298 (2011).

Riga, A., Soutsas, K., Ntampegliotis, K., Karayannis, V., Papapolymerou G., (2007), Effect of System Parameters and of Inorganic Salts on the Degradation Kinetics of Procion Hexl Dyes. Comparison of $\mathrm{H}_{2} \mathrm{O}_{2} / \mathrm{uv}$, Fenton, and photo-Fenton, $\mathrm{TiO}_{2} / \mathrm{UV}$ and $\mathrm{TiO}_{2} / \mathrm{UV} / \mathrm{H}_{2} \mathrm{O}_{2}$ processes, Desalination, 211, 72-86.

Pozzo, R., Baltanás, M., Cassano, A., Supported titanium oxide as photocatalyst in water decontamination: State of the art, Catalysis Today, 39 (3), 1997, 219-231.

Rozas, O., Contreras, D., Mondaca, M.A., Pérez-Moya, M., Mansilla, H.D., (2010), Experimental design of Fenton and photo-Fenton reactions for the treatment of ampicillin solutions. J. Hazard. Mater. 177, 1025-1030.

Shimizu N., Ogino C., Farshbaf Dadjour M., Murata T., (2007), Sonocatalytic degradation of methylene blue with TiO2 pellets in water, Ultrasonics Sonochemistry, 14, 184-190.

Siedlecka, E. M., Wieckowska, A., Stepnowski, P. (2007), Influence of inorganic ions on MTBE degradation by Fenton's reagent, Journal of Hazardous Materials, 147, 497-502.

Spacek, W., Bauer, R., Heisler, G., (1995), Heterogeneous and homogeneous wastewater treatment Comparison between photodegradation with $\mathrm{TiO}_{2}$ and the photo-Fenton 'reaction, Chemosphere 30, 477-484.

Trovó, A.G., Nogueira, R.F.P., Agüera, A., Fernandez-Alba, A.R., Malato, S., (2011), Degradation of the antibiotic amoxicillin by photo-Fenton process - Chemical and toxicological assessment. Water Res. 45, 1394-1402.

Venkata K., Rao S., Subrahmanyam M., Boule P., (2004), Immobilized $\mathrm{TiO}_{2}$ photocatalyst during long-term use: decrease of its activity, Applied Catalysis B: Environmental 49239 249.

Vinita M., Dorathi R. P. J., Palanivelu K., (2010), Degradation of 2,4,6-trichlorophenol by photo Fenton's like method using nano heterogeneous catalytic ferric ion, Solar Energy, 84, 1613-1618.

Vlazan P., Vasile M., (2010), Synthesis and characterization $\mathrm{CoFe}_{2} \mathrm{O}_{4}$ nanoparticles prepared by the hydrothermal method; Optoelectronics and Advanced Materials-Rapid Communications; 4; 1307-1309;

$\mathrm{Xu}$, Hongwu, Zhang, Yiping, Navrotsky, Alexandra, (2001), Enthalpies of formation of microporous titanosilicates ETS-4 and ETS-10, Microporous and Mesoporous Materials, 47, 2-3, 285-291.

Zhou H., Smith, D.W., (2002), Advanced technologies in water and wastewater treatment, J. Environ. Eng. Sci. 1: 247-264.

Zazo J. A., Casas J. A., Mohedano A. F., Gilarranz M. A., Rodríguez J. J., (2005), Chemical Pathway and Kinetics of Phenol Oxidation by Fenton's Reagent, Environmental Science and Technology, 39, 9295-9302.

Wang H., Wang J., (2007), Electrochemical degradation of 4-chlorophenol using a novel $\mathrm{Pd} / \mathrm{C}$ gas-diffusion electrode, Applied Catalysis B; Environmental, 77, 58-65. 
Yu Y., Ding Y., Zuo S., Liu J., (2011) Photocatalytic Activity of Nanosized Cadmium Sulfides Synthesized by Complex Compound Thermolysis, International Journal of Photoenergy, 15 ; 